\section{Commentary: How long it takes is not as important as how long it lasts}

\author{
Gaetano Paone, MD, MHSA
}

Transcatheter aortic valve replacement (TAVR) has been approved for patients with severe aortic stenosis at all levels of risk, and is now performed in more than 700 centers. In fact, annual TAVR volume, for the first time in 2019, exceeded the total number of surgical AVR procedures. ${ }^{1-4}$ At least in part to make the surgical approach more palatable to patient preference compared with TAVR, access through smaller, less invasive hemisternotomy or right thoracotomy incisions has increased, with excellent outcomes. ${ }^{5}$

Sutureless or rapid deployment valves have been developed ostensibly to simplify the process of surgical AVR and further facilitate more frequent implantation via these less invasive approaches. ${ }^{6,7}$ Unlike with TAVR, the native valve leaflets are removed and the annulus is decalcified, presumably allowing more precise positioning and annular coaptation under vision. Cardiopulmonary bypass and crossclamp times have been approximately 30 minutes shorter than generally seen when implanting stented devices, although whether this difference, for AVR alone or with concomitant procedures, is clinically significant is uncertain. Early hemodynamic performance seems good, especially in smaller valve sizes, perhaps obviating need for annular enlargement procedures in some. ${ }^{8}$

Fischlein and colleagues ${ }^{9}$ report midterm outcomes at mean follow-up of 3.8 years from 658 patients enrolled to receive the Perceval sutureless valve (LivaNova, PLC, London, United Kingdom) in the multicenter European Cavalier Trial between 2010 and 2013. With mean age of

\footnotetext{
From the Division of Cardiothoracic Surgery, Structural Heart and Valve Center, Emory University School of Medicine, Atlanta, Ga.

Disclosures: Dr Paone is a consultant and proctor for Edwards Lifesciences and owns equity in Medtronic, PLC.

The Journal policy requires editors and reviewers to disclose conflicts of interest and to decline handling or reviewing manuscripts for which they may have a conflict of interest. The editors and reviewers of this article have no conflicts of interest.

Received for publication Dec 21, 2020; revisions received Dec 21, 2020; accepted for publication Dec 22, 2020; available ahead of print Dec 31, 2020.

Address for reprints: Gaetano Paone, MD, MHSA, Division of Cardiothoracic Surgery, Structural Heart and Valve Center, Emory University Midtown Hospital, 550 Peachtree St, NE, Davis-Fischer Bldg, 4th Floor, Atlanta, GA 30308 (E-mail: gaetano.paone@emory.edu).

J Thorac Cardiovasc Surg 2022;164:1781-2

$0022-5223 / \$ 36.00$

Copyright (c) 2020 by The American Association for Thoracic Surgery

https://doi.org/10.1016/j.jtcvs.2020.12.105
}

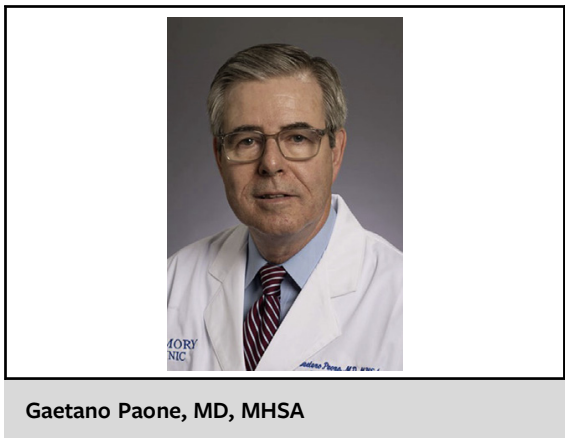

CENTRAL MESSAGE

Encouraging midterm results for the Perceval valve require longerterm outcomes, including valve durability, to determine its future role in surgical versus catheterbased aortic valve replacement.

$78.3 \pm 5.6$ years and Society of Thoracic Surgeons predicted risk score of $7.2 \pm 7.4$, 30-day mortality was $3.7 \%$, with $72.7 \%$ survival at 5 years. Periprocedural stroke occurred in $2.4 \%$ with moderate/severe perivalvular aortic insufficiency in $0.8 \%$. Hemodynamic function was stable out to 5 years. Approximately one-third of procedures were performed via ministernotomy.

However, valve implantation was unsuccessful in 30 patients and almost half those implanted discontinued the study; 154 deaths, 109 patients withdrawn or lost to follow-up, and 30 patients who underwent valve explant or reintervention (including 13 with early structural deterioration). Also, those with more than mild central aortic insufficiency increased from $0.6 \%$ at discharge to $7.5 \%$ at 5 years. The authors suggest suboptimal valve sizing and/or device positioning as possible causes, and stress the need to "focus on decalcification, sizing, use of guiding sutures, and valve deployment" as "critical aspects of the procedure," which is to say all aspects of the procedure are critical to success.

However small the incision and shorter the times, access to the chest, cardiopulmonary bypass, and aortic crossclamping are still required. It therefore seems unlikely this approach will replace TAVR to any significant extent in intermediate- and high-risk patients. On the other hand, the treatment algorithm for those at low risk, particularly of younger age, is less clearly defined and continues to evolve. Initial decision making requires planning for 
subsequent valve-in-valve options, coronary access, and the risks of reoperation and valve explant, with much of the data needed to make these decisions still in the future. Is there a role for the Perceval valve in this paradigm? The results thus far are encouraging; however, longer-term follow-up, particularly regarding valve durability for this and other catheter-based devices, is clearly needed.

\section{References}

1. Mack MJ, Leon MB, Thourani VH, Makkar R, Kodali SK, Russo M, et al. Transcatheter aortic-valve replacement with a balloon-expandable valve in low-risk patients. N Engl J Med. 2019;380:1695-705.

2. Carrol JD, Mack MJ, Vemulapalli S, Herrmann HC, Gleason TG, Hanzel G, et al. STS-ACC TVT Registry of Transcatheter Aortic Valve Replacement. Ann Thorac Surg. 2020;76:2492-516.

3. Popma JJ, Deep M, Yakubov SJ, Mumtaz M, Gada H, O'Hair D, et al. Transcatheter aortic valve replacement with a self-expanding valve in low-risk patients. $N$ Engl J Med. 2019;380:1706-15.
4. Makkar RR, Thourani VH, Mack MJ, Kodali SK, Kapadia S, Webb JG, et al. Fiveyear outcomes of transcatheter or surgical aortic-valve replacement. $N$ Engl J Med. 2020;382:799-809.

5. Ghoreishi M, Thourani VH, Badhwar V, Malek Massad M, Svensson L, Taylor BS, et al. Less-invasive aortic valve replacement: trends and outcomes from the STS Database. Ann Thorac Surg. August 21, 2020 [Epub ahead of print].

6. Fischlein T, Meuris B, Hakim-Meibodi K, Misfeld M, Carrel T, Zembala M, et al. The sutureless aortic valve at 1 year: a large multicenter cohort study. J Thorac Cardiovasc Surg. 2016;151:1617-26.

7. Borger MA, Moustafine V, Conradi L, Knosalla C, Richter M, Merk DR, et al. A randomized multicenter trial of minimally invasive rapid deployment versus conventional full sternotomy aortic valve replacement. Ann Thorac Surg. 2015;99: $17-25$.

8. Shalabi A, Spiegelstein D, Sternik L, Feinberg MS, Kogan A, Levin S, et al. Sutureless versus stented valve in aortic valve replacement in patients with small annulus. Ann Thorac Surg. 2016;102:118-22.

9. Fischlein T, Meuris B, Folliguet T, Hakim-Meibodi K, Misfeld M, Carrel $\mathrm{T}$, et al. Midterm outcomes with a sutureless aortic bioprosthesis in a prospective multicenter cohort study. J Thorac Cardiovasc Surg. 2022; 164:1772-80.e11.
See Article page 1772.

\section{Commentary: The truth is out there}

\author{
Fabio Barili, MD, PhD, FESC, ${ }^{\mathrm{a}}$ and \\ Alessandro Parolari, $\mathrm{MD}, \mathrm{PhD}^{\mathrm{b}}$
}

We are focusing on the new, we are distracting from the old. The rapid development of transcatheter devices and the subsequent flourishing of randomized clinical trials and large registries have shown not only the feasibility and good results of new technologies but have also brought to light that something is missing, rigorous data on surgical aortic valve replacement (SAVR) ${ }^{1,2}$ A critical appraisal of recent randomized clinical trials can suggest that incidence of end

From the a Department of Cardiac Surgery, Santa Croce Hospital, Cuneo, Italy; and ${ }^{\mathrm{b}}$ University Department of Cardiac Surgery, IRCCS Policlinico San Donato, San Donato, Italy.

Disclosures: Fabio Barili reported personal fees from Abbott, outside the present work. Alessandro Parolari reported no conflicts of interest.

The Journal policy requires editors and reviewers to disclose conflicts of interest and to decline handling or reviewing manuscripts for which they may have a conflict of interest. The editors and reviewers of this article have no conflicts of interest.

Received for publication Jan 5, 2021; revisions received Jan 5, 2021; accepted for publication Jan 6, 2021; available ahead of print Jan 20, 2021.

Address for reprints: Fabio Barili, MD, PhD, FESC, Department of Cardiac Surgery, Santa Croce Hospital, Via M. Coppino 26, 12100 Cuneo, Italy (E-mail: fabarili@ libero.it or barili.f@ospedale.cuneo.it).

J Thorac Cardiovasc Surg 2022;164:1782-3

$0022-5223 / \$ 36.00$

Copyright (c) 2021 by The American Association for Thoracic Surgery

https://doi.org/10.1016/j.jtcvs.2021.01.020

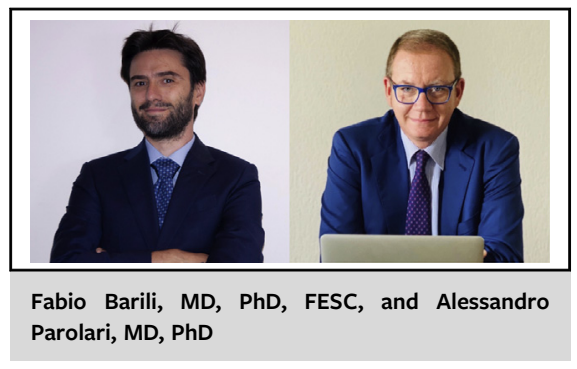

CENTRAL MESSAGE

The 5-year outcomes of suture-

less aortic valve bioprostheses

are a key point for remodulating

the reference points for bench-

marking of aortic valve

treatment. points in the SAVR arm are abnormally high compared with the real world; nonetheless, looking for high-quality data supporting this hypothesis, we stay with a fistful of flies in hand as there are no strong updated mid- and long-term outcomes confirming surgery as the gold standard for the treatment of aortic valve disease, until proven otherwise.

The 5-year follow-up presented by Fischlein and colleagues ${ }^{3}$ adds new information on the outcomes of sutureless aortic valve bioprostheses and can permit us to make 